\title{
QT dispersion as a risk factor for sudden cardiac death and fatal myocardial infarction in a coronary risk population
}

\author{
Matti Mänttäri, Lasse Oikarinen, Vesa Manninen, Matti Viitasalo
}

\begin{abstract}
Objective-To test in a prospective study the hypothesis that increased QT dispersion in resting 12-lead ECG is a predictor of sudden cardiac death.

Design-A nested case-control study during a mean (SD) follow up time of 6.5 $(2 \cdot 8)$ years.

Setting-A prospective, placebo controlled, coronary prevention trial with gemfibrozil among dyslipidaemic middle aged men in primary (occupational) health care units: the Helsinki heart study.

Patients-24 victims of fatal myocardial infarction, 48 victims of sudden cardiac death without acute myocardial infarction, and their matched controls.

Main outcome measures-QT dispersion in baseline and pre-event electrocardiograms.

Results-At study baseline, QT dispersion was similar in all victims and controls. When estimated from the pre-event ECG on average 14 months before death, the risk of sudden cardiac death in the highest $Q T_{\text {PEAK (up to the peak of the } T}$ wave) dispersion tertile ( $\geqslant 50 \mathrm{~ms}$ ) was $6 \cdot 2$-fold $(95 \%$ confidence interval 1.7 to 23.5) compared with the risk in the lowest tertile ( $\leqslant 30 \mathrm{~ms})$, and $4 \cdot 9$-fold $(1 \cdot 2$ to $19 \cdot 5)$ after adjustment for the presence of left ventricular hypertrophy, while $\mathbf{Q T}_{\mathrm{PEAK}}$ dispersion could not predict fatal myocardial infarction. $Q T_{\mathrm{END}}$ dispersion (up to the end of the $T$ wave) in pre-event ECGs could not discriminate victims of either sudden cardiac death or fatal myocardial infarction from their matched controls. Conclusions-In middle aged men with a normal conventional QT interval in 12lead resting ECG, increased $Q T_{P E A K}$ dispersion is an independent risk factor for sudden cardiac death, but not for fatal myocardial infarction.
\end{abstract}

(Heart 1997;78:268-272)

Keywords: QT interval; QT dispersion; sudden cardiac death; myocardial infarction

With few exceptions, sudden cardiac death in middle aged and elderly populations is associated with coronary heart disease. It is the first manifestation in some $20 \%$ of cases and constitutes about half of all coronary deaths. Most sudden cardiac deaths are caused by arrhyth- mias and $65 \%$ to $85 \%$ of victims of prehospital cardiac arrest have ventricular fibrillation as the causative arrhythmia. ${ }^{1-4}$ The prevalence of a plaque rupture plus occluding thrombus as an initiating factor varies from $10 \%$ to $75 \%$, depending on the population and definition of sudden cardiac death. ${ }^{5-8}$ Most of the classical coronary risk factors also predict sudden cardiac death, ${ }^{9-13}$ and several clinical and electrophysiological variables, such as ejection fraction, ${ }^{14}$ presence of non-sustained ventricular tachycardia, ${ }^{15}$ late potentials, ${ }^{16}$ heart rate variability, ${ }^{17} \mathrm{~T}$ wave alternans, ${ }^{18}$ or inducibility of ventricular arrhythmias in electrophysiological stimulation, ${ }^{19}$ have been studied as predictors of sudden cardiac death. However, low specificity or complicated recording procedures have so far hindered their widespread use.

QT dispersion - that is, inter-lead variability in the QT intervals - is considered to reflect regional variation in ventricular recovery times. This spatial dispersion of repolarisation could offer an electrophysiological substrate for malignant ventricular arrhythmias. ${ }^{20-23}$ Recent clinical data suggest that QT dispersion, as measured from a 12-lead surface electrocardiogram, might offer a non-invasive marker for susceptibility to life threatening arrhythmias and hence sudden cardiac death. ${ }^{24-27} \mathrm{We}$ tested this hypothesis in middle aged dyslipidaemic male participants of the Helsinki heart study. This particular study cohort consisted of 24 victims of fatal myocardial infarction, 48 sudden cardiac death victims without signs of acute myocardial infarction, and matched controls, with a mean (SD) follow up time of $6.5(2.8)$ years. The study design allowed us to measure the QT dispersion in electrocardiograms recorded both at study baseline and on average 14 (13) months before death.

\section{Methods}

The study cohort originate from the Helsinki heart studies, which were placebo controlled coronary prevention trials ${ }^{28-30}$ among dyslipidaemic middle aged ( 40 to 55 years) male employees of the Finnish State Railways, Posts and Telecom, and five industrial companies. The sudden cardiac death victims were subjects who experienced by study protocol either a sudden cardiac death or unwitnessed cardiac death during 1981-92. A one hour limit for the duration of symptoms was used in the definition of sudden cardiac death, while unwitnessed cardiac death was diagnosed when there was insufficient preterminal data for 
classification as sudden cardiac death. In this paper these two end points are collectively called sudden cardiac deaths.

Of the 241 cardiac end points occurring in the Helsinki heart study primary prevention trial during the extended follow up, ${ }^{30} 189$ consisted of non-fatal myocardial infarctions, 24 were classified as fatal myocardial infarctions, and 28 as sudden cardiac deaths. A diagnosis of fatal myocardial infarction was based on sufficient preterminal data $(n=7)$ or on necropsy verification of an occluding thrombus and a fresh myocardial lesion $(n=17)$. The matched controls for fatal myocardial infarctions consisted of men who completed the study period without coronary events. Two matching variables, the geographical area and the treatment group, were used. Sudden cardiac death was diagnosed at necropsy when myocardial infarction was excluded and the ventricular wall appeared homogeneous in cross sections and no occluding thrombi were found. A detailed description of the criteria for Helsinki heart study cardiac end points is found elsewhere. ${ }^{28}$

Of the 28 sudden cardiac deaths in the primary prevention trial, one was excluded from the analyses because of atrial fibrillation and a second because of technical difficulties in the interpretation of the electrocardiogram. The primary sudden cardiac deaths (figure) thus consisted of these 26 victims up to 1990 plus five additional subjects with necropsy data who experienced a sudden cardiac death as their first coronary event in 1991-92. The necropsy rate among victims of primary sudden cardiac death was $71 \%$ (22 out of 31 ). The primary controls were men without coronary events during the follow up, matched for drug treatment (gemfibrozil/placebo) and geographical area. The latter was necessary to ensure the use of the same ECG recorder for both case and control.

The secondary cases of sudden cardiac death (figure) consisted of 17 subjects who suffered sudden cardiac death after first experiencing a non-fatal myocardial infarction. Eleven subjects had their infarcts before the start of the Helsinki heart study and were fol-

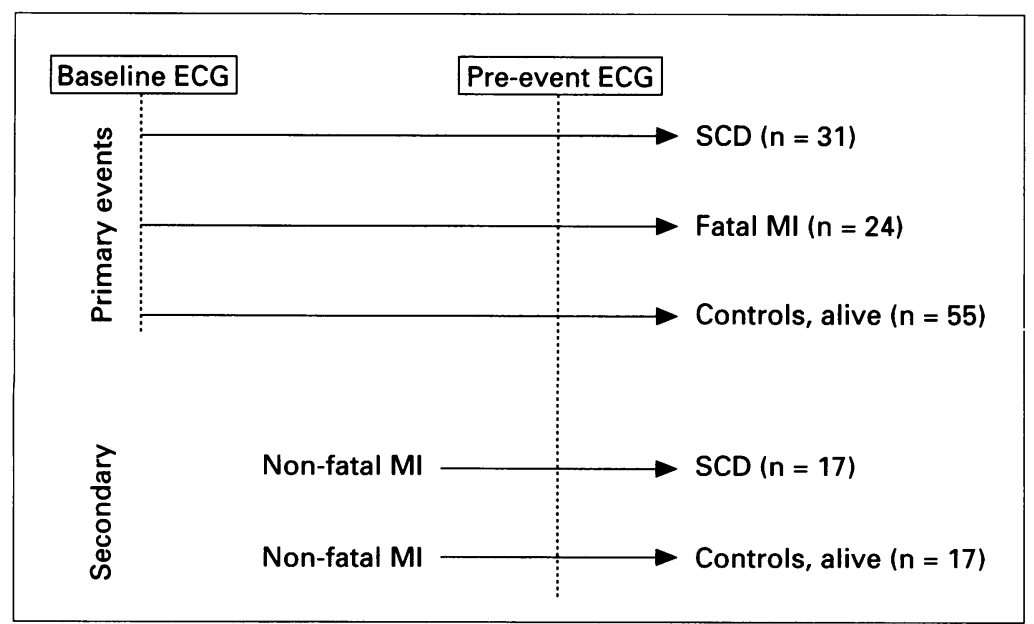

Study design and timing of the ECG recordings. SCD, sudden cardiac death; $M I$, myocardial infarction. lowed up in the secondary prevention study. ${ }^{29}$ The necropsy rate in victims of secondary sudden cardiac death was $65 \%$ (11 out of 17 ). The secondary controls were men who experienced a non-fatal myocardial infarct in the primary prevention trial but who remained alive until the end of follow up. In addition to drug treatment and geographical area, the secondary controls were also matched with regard to the localisation of the myocardial infarct (five anterior, 11 inferior, and one with undefined localisation).

\section{RECORDING OF THE ELECTROCARDIOGRAMS} AND QT MEASUREMENTS

A resting 12-lead electrocardiogram was recorded at the second screening visit in 1981-82 and this is referred to as the baseline electrocardiogram in this paper. During the study period, a routine electrocardiogram was recorded annually and whenever the subject complained of symptoms suggesting myocardial infarction. The last available recording before death is referred to as a pre-event electrocardiogram in this paper. The mean (SD) time interval between pre-event electrocardiogram and death was 14 (13) months. The time interval from nonfatal myocardial infarction to pre-event electrocardiogram was $2.8 \quad(1.9)$ years in victims of secondary sudden cardiac death. The electrocardiograms for the controls were selected from the same visits as for the cases, so the time intervals in all case-control pairs are identical.

All QT intervals were measured from standard 12-lead electrocardiograms using a paper speed of $50 \mathrm{~mm} / \mathrm{s}$ and a calibration of $10 \mathrm{~mm} / \mathrm{mV}$. One blinded investigator (LO) made all the measurements manually with the recordings in random order and without any clinical data. Three consecutive beats in each lead was measured using accuracy of $10 \mathrm{~ms}$ $(10 \mathrm{~ms}=0.5 \mathrm{~mm}$ when the paper speed is 50 $\mathrm{mm} / \mathrm{s}$ ) and the mean of these was used as the QT interval.

The $\mathrm{QT}_{\mathrm{END}}$ interval was measured from the onset of the QRS complex to the end of the T wave, defined as the return to the T-P baseline. If the $T$ wave was interrupted by a $U$ wave before return to the baseline, the $\mathrm{QT}_{\mathrm{END}}$ interval was measured to the nadir between $T$ and $U$ waves. If the end of the $T$ wave could not be clearly determined, the lead was excluded from the analyses. A mean of 11.3 leads (range 7 to 12) per ECG was measured to estimate $\mathrm{QT}_{\mathrm{END}}$ dispersion in sudden cardiac death cases, while the corresponding numbers in controls were $11 \cdot 2$ (range 8 to 12 ).

The $\mathrm{QT}_{\mathrm{PEAK}}$ interval was measured from the onset of the QRS complex to the peak of the T wave, defined as the centre of the highest amplitude of the $T$ wave. In cases of biphasic $T$ waves, no $\mathrm{QT}_{\mathrm{PEAK}}$ intervals were recorded in those leads. The $T$ wave was considered biphasic if after the first $T$ wave peak there was a second $T$ wave peak of opposite direction (negative-positive or positive-negative), and the time interval between these two was less than $150 \mathrm{~ms}^{31} \mathrm{QT}_{\mathrm{PEAK}}$ dispersion was estimated from a mean of $10 \cdot 7$ (range 7 to 12 ) 
Table 1 QT dispersion in victims of sudden cardiac death (SCD), fatal myocardial infarction (MI), and matched controls. Findings in pre-event electrocardiograms

\begin{tabular}{|c|c|c|c|c|c|c|}
\hline & \multicolumn{2}{|c|}{ Primary $S C D$} & \multicolumn{2}{|c|}{ Secondary SCD } & \multicolumn{2}{|l|}{ Fatal MI } \\
\hline & Victims & Controls & Victims & Controls & Victims & Controls \\
\hline $\begin{array}{l}\text { Number } \\
\mathrm{QT}_{\mathrm{PEAK}} \text { dispersion, mean (SD) ms } \\
\mathrm{QT}_{\mathrm{END}} \text { dispersion, mean (SD) ms }\end{array}$ & $\begin{array}{l}31 \\
43(18) \\
45(16)\end{array}$ & $\begin{array}{l}31 \\
35(14)^{\star} \\
43(16) \ddagger\end{array}$ & $\begin{array}{l}17 \\
56(16) \\
51(19)\end{array}$ & $\begin{array}{l}17 \\
44(20) \dagger \\
54(30) \ddagger\end{array}$ & $\begin{array}{l}24 \\
36(13) \\
41(15)\end{array}$ & $\begin{array}{l}24 \\
35(11) \ddagger \\
43(14) \ddagger\end{array}$ \\
\hline
\end{tabular}

Primary indicates SCD as the first cardiac event and secondary after a non-fatal MI.

${ }^{\star} P<0.03$ between cases and controls; $+\mathrm{P}<0.04$ between cases and controls; $\mathrm{P}<0.01$ between all $S C D$ cases and controls (ANOVA); $¥ \mathrm{P}=\mathrm{NS}$ between cases and controls.

measured leads in sudden cardiac death cases and from a mean of 10.6 (range 6 to 12) measured leads in controls. The longest and shortest QT intervals in any of the 12 leads were recorded and the difference between these two is the QT dispersion. It should be noted, that no bundle branch blocks were observed in the study cohort.

The interobserver variability of the measurements was estimated by comparing the results in a random $25 \%$ sample of all electrocardiograms, which were blindly remeasured by an experienced electrophysiologist (MV). No differences emerged in the means of all measured $\mathrm{QT}_{\mathrm{END}}$ intervals (369v370 ms) or $\mathrm{QT}_{\text {PEAK }}$ intervals (302 v $300 \mathrm{~ms}$ ) between observers, the corresponding coefficients of variations being $1.9 \%$ in $\mathrm{QT}_{\mathrm{END}}$ measurements and $2.0 \%$ in $\mathrm{QT}_{\mathrm{PEAK}}$ measurements. The limits of agreement calculated according to the method of Bland and Altman ${ }^{32}$ were from -11.4 to $+13.8 \mathrm{~ms}$ for $\mathrm{QT}_{\mathrm{END}}$ measurements and -11.8 to $+8.6 \mathrm{~ms}$ for $\mathrm{QT}_{\mathrm{PEAK}}$ measurements.

There was a close correlation between heart rate and maximum $\mathrm{QT}_{\mathrm{PEAK}}$ interval $(r=$ $-0.68, \mathrm{P}<0.001)$ and $\mathrm{QT}_{\mathrm{END}}$ interval $(r=$ $-0.73, \mathrm{P}<0.001)$ as well as between heart rate and minimum $\mathrm{QT}_{\mathrm{PEAK}}$ interval $(r=$ $-0.76, \mathrm{P}<0.001)$ and $\mathrm{QT}_{\mathrm{END}}$ interval $(r=$ $-0.74, P<0.001)$. However, the association between $\mathrm{QT}_{\mathrm{END}}$ dispersion and heart rate was weaker $(r=-0.24, \mathrm{P}<0.02)$ and no correlation existed between heart rate and $\mathrm{QT}_{\mathrm{PEAK}}$ dispersion $(r=0.02, \mathrm{P}=0 \cdot 7)$. For these reasons, the data on maximum QT intervals in this paper are corrected for heart rate using a nomogram, tested in our population, ${ }^{33}$ while QT dispersion is presented without rate correction.

STATISTICAL METHODS

Values are given as mean (SD). The differences in mean levels between the groups in continuous variables were estimated using

Table 2 Maximum $Q T_{P E A K}$ interval and $Q T_{P E A K}$ dispersion in pre-event electrocardiograms as risk factors for sudden cardiac death. Odds ratios and $95 \%$ confidence intervals

\begin{tabular}{lll}
\hline & Unadjusted & Adjusted for $L V H^{\star}$ \\
\hline QT $_{\text {PEAK dispersion }}$ & & \\
1 st tertile $(\leqslant 30 \mathrm{~ms})$ & 1 & 1 \\
2nd tertile $(40 \mathrm{~ms})$ & $3.4(1.0$ to 11.5$)$ & $3.5(0.9$ to 12.4$)$ \\
3rd tertile $(\geqslant 50 \mathrm{~ms})$ & $6 \cdot 2(1.7$ to 23.5$)$ & $4.9(1.2$ to 19.5$)$ \\
& $\mathrm{P}<0.01$ for trend & \\
Maximum $\mathrm{QT}_{\text {PEAK }}$ interval & 1 & 1 \\
1st tertile $(\leqslant 339 \mathrm{~ms})$ & $1.9(0.7$ to 5.4$)$ & $1.9(0.7$ to $5 \cdot 0)$ \\
2nd tertile $(340-359 \mathrm{~ms})$ & $5 \cdot 3(1.5$ to $18 \cdot 6)$ & $4.6(1.2$ to $17 \cdot 0)$ \\
3rd tertile $(\geqslant 360 \mathrm{~ms})$ & $\mathrm{P}<0.02$ for trend & \\
&
\end{tabular}

Values are odds ratios (95\% confidence intervals)

$\star$ Presence (yes/no) of left ventricular hypertrophy $(\mathrm{SV} 1+\mathrm{RV} 5 \geqslant 35 \mathrm{~mm})$ either the $t$ test or analysis of variance (ANOVA). The differences in discrete variables were estimated using either Fisher's exact test or the $\chi^{2}$ test. The significances of maximum $\mathrm{T}$ intervals and QT dispersion indices as coronary risk factors were estimated using a nested case-control design and conditional logistic regression analyses in the EGRET (Epidemiology and Statistics Corporation, Seattle, Washington, USA). For the analyses, the intervals and dispersion indices in the study population were divided into tertiles and the lowest was used as a reference (odds ratio = 1). The cut off limits for the highest tertiles were at the levels of the 90th to 95th centiles of those detected in primary controls.

\section{Results}

No significant differences between sudden cardiac death victims and matched controls emerged in any of the measured QT intervals or QT dispersions determined from baseline electrocardiograms (data not presented). In contrast, the victims of sudden cardiac death had significantly longer maximum $\mathrm{QT}_{\mathrm{PEAK}}$ intervals (359 (24) v 344 (21) ms; P < 0.002) and significantly greater $\mathrm{QT}_{\mathrm{PEAK}}$ dispersion (table 1) in pre-event electrocardiograms compared to controls. The corresponding differences in maximum $\mathrm{QT}_{\mathrm{END}}$ interval (421 $v 414 \mathrm{~ms}$ ) and $\mathrm{QT}_{\mathrm{END}}$ dispersions (47 $v 47 \mathrm{~ms}$ ) were not statistically significant. No differences in any of the determined QT intervals or QT dispersions were found in either baseline or pre-event electrocardiograms between subjects with fatal myocardial infarction and matched controls.

The mean duration of the QRS complex was similar in controls, 91 (12) $\mathrm{ms}$, and in subjects with sudden cardiac death, 95 (11) ms, or fatal myocardial infarction, 94 (10) ms. No difference in systolic blood pressure was found between sudden cardiac death victims and controls, but diastolic blood pressure was higher, at 95 (12) v 89 (10) $\mathrm{mm} \mathrm{Hg}(\mathrm{P}<0.01)$, and left ventricular hypertrophy (defined as SV1 + RV5 $\geqslant 35 \mathrm{~mm}$ ) was more prevalent in victims (23\% $v 4 \% ; \mathrm{P}<0.02)$. The mean heart rate was similar in sudden cardiac death cases and controls $(66 v 66 / \mathrm{min})$ and only two subjects had a resting heart rate of more than $90 / \mathrm{min}$, a level shown to discriminate between victims and controls. ${ }^{13}$

Alcohol consumption was higher in sudden cardiac death victims than in controls $(71 \% v$ $39 \%$ in the highest tertile of consumption; $\mathrm{P}<$ 0.01 ). Mean serum total and HDL cholesterol were similar, while triglycerides, probably due to alcohol consumption, were higher in victims, 
at $2.9(3.0)$ v $1.9(1.3) \mathrm{mmol} / \mathrm{l} ; \mathrm{P}<0.04$. The prevalence of smoking was similar in both groups $(56 \% v 51 \%)$, as well as the mean ages ( $48.6 v 49.0$ years).

Of the potential confounding variables, the presence of left ventricular hypertrophy had no influence on $\mathrm{QT}_{\mathrm{PEAK}}$ dispersion, neither were any associations found between QT dispersion and the use of $\beta$ blocking drugs. Alcohol consumption increased the dispersion in controls, while it had no effect in sudden cardiac death victims (data not presented). A positive association $(r=0.36, \quad \mathrm{P}<0.03)$ was detected between the age at death and the $\mathrm{QT}_{\mathrm{PEAK}}$ dispersion.

Conditional logistic regression analyses disclosed a significant "dose-response" pattern between increasing maximum $\mathrm{QT}_{\mathrm{PEAK}}$ interval or $\mathrm{QT}_{\mathrm{PEAK}}$ dispersion and the risk of sudden cardiac death. (table 2). Adjustment for the presence of left ventricular hypertrophy had only marginal influence on the risk patterns, and additional adjustment for age in the model had no further impact.

The necropsy findings in 22 victims of primary sudden cardiac death showed that, with the exception of three subjects, all had significant coronary heart disease with atherosclerotic lesions in coronary arteries. By definition, however, no occluding thrombi or fresh myocardial lesions were detected. Five subjects had a scar in the left ventricle, indicating a healed myocardial infarct. None of these participants in the primary prevention trial had ever revealed either a history of a previous myocardial infarct or electrocardiographic evidence of infarction. The distribution of coronary disease was similar in those who suffered either a sudden cardiac death or an unwitnessed cardiac death according to the original Helsinki heart study end point definitions. By definition, all 17 necropsied victims of primary fatal myocardial infarction showed significant coronary disease with advanced atherosclerosis, occluding thrombi, and fresh myocardial infarcts.

\section{Discussion}

Our results suggest that in middle aged men with normal QT interval, increased $\mathrm{QT}_{\mathrm{PEAK}}$ dispersion and increased duration of the maximum $\mathrm{QT}_{\mathrm{PEAK}}$ interval are independent risk factors for sudden cardiac death, but not for fatal myocardial infarction.

QT interval is conventionally measured to the end of the $T$ wave and this time interval is considered to represent electrical repolarisation of the myocardium. The spatial dispersion of the repolarisation times, a possible determinant of malignant ventricular arrhythmias, is then measured as inter-lead variability of these $\mathrm{QT}_{\mathrm{END}}$ intervals. In our prospective coronary risk cohort neither $\mathrm{QT}_{\mathrm{END}}$ interval nor the $\mathrm{QT}_{\mathrm{END}}$ dispersion could predict sudden cardiac death, whereas prolonged $\mathrm{QT}_{\mathrm{PEAK}}$ interval and increased $\mathrm{QT}_{\mathrm{PEAK}}$ dispersion were significant predictors. Electrophysiologically, the peak of the $T$ wave is thought to represent the moment of maximum net extracellular field produced by spreading of the repolarisation wave throughout the ventricular myocardium. ${ }^{34}$ Drug experiments by El-Sherif et al have shown that the dispersion of the myocardial rather than endocardial or epicardial action potential durations is critical for polymorphic ventricular tachycardia. ${ }^{35}$ The present findings suggest that in a population with normal repolarisation times, the timing and the dispersion of the spatial repolarisation force-that is, the repolarisation of the myocardial layer-rather than the duration or dispersion of the whole repolarisation are important in the genesis of malignant arrhythmias in an ischaemic heart.

Our data suggest that increased $\mathrm{QT}_{\mathrm{PEAK}}$ dispersion might develop with coronary disease in some individuals, predisposing them to sudden cardiac death, although it seem probable that the development of coronary disease alone does not necessarily increase the $\mathrm{QT}_{\mathrm{PEAK}}$ dispersion. The lack of a unified protocol for necropsies renders these conclusions only suggestive. An argument against a simple association between coronary heart disease and $\mathrm{QT}_{\mathrm{PEAK}}$ dispersion derives from the fact that $\mathrm{QT}_{\mathrm{PEAK}}$ dispersion was always greater in victims of sudden cardiac death, irrespective of whether the death was the first manifestation of coronary disease or a secondary event after a non-fatal myocardial infarct. Another opposing argument arises from the fact that $\mathrm{QT}_{\mathrm{PEAK}}$ dispersion could not discriminate between victims of fatal myocardial infarction and controls. Thrombolytic treatment has been shown to reduce QT dispersion, ${ }^{36}$ but the Helsinki heart study was conducted before the thrombolytic era, so only one victim of secondary sudden cardiac death had received streptokinase in conjunction with acute myocardial infarction.

A problem in the study of sudden cardiac death is the initiating events for arrhythmias. Population based necropsy data suggest that in $10-75 \%$ of cases classified as sudden coronary deaths the main cause is an unstable atherosclerotic plaque, with disruption and accumulation of a fresh thrombus..$^{5-8}$ Because of the Helsinki heart study criteria for sudden cardiac and unwitnessed deaths, our victims consisted of subjects in whom an acute myocardial infarct as the propagating event was excluded. Of course we can never totally exclude the possibility of an infarct in the one third of sudden cardiac death victims without necropsy. Furthermore, routine necropsy may not disclose hyperacute changes of infarction, since several hours may be required before myocardial infarction is detectable histologically in routine samples. When acute myocardial infarction is excluded as an initiator, ventricular fibrillation can be either a primary arrhythmic event or induced by ischaemia. While the latter seems more relevant in our population with coronary heart disease, our data are insufficient for further speculations of the eventual mechanisms.

In spite of the fact that our patient material was highly selected, the classical risk factors of sudden cardiac death detected in a general population, such as hypertension and left ventricular hypertrophy, were also significant determinants in our dyslipidaemic cohort, where even some of the controls had suffered a previous myocar- 
dial infarction. Our results are also in agreement with the concept of the time dependence of the risk factors for sudden cardiac death, ${ }^{1011}$ with the classical coronary risk factors being better long term predictors, while the electrocardiographic variables are more powerful for short term prediction of sudden cardiac death. ${ }^{12}$ The increased $\mathrm{QT}_{\mathrm{PEAK}}$ dispersion in our population is a short term risk factor since no difference in dispersion between victims and controls could be detected in baseline electrocardiograms.

Our study has some shortcomings and restrictions. The study population consisted of middle aged Caucasian males, and the results may not be applicable to other races or to women. One might also argue against pooling subjects with sudden cardiac death and unwitnessed cardiac deaths. However, in most cases the victims of unwitnessed deaths were found in circumstances suggesting normal daily activities before death, so it may not be unjustified to categorise these as sudden cardiac deaths, provided that other vascular catastrophes and causes of death are excluded. This view is supported by our necropsy data, which suggest that at least in dyslipidaemic middle aged men the prevalence of coronary heart disease is similar in victims of unwitnessed and sudden cardiac death.

The clinical relevance of increased $\mathrm{QT}_{\mathrm{PEAK}}$ dispersion in routine ECG should be considered in the context of the eventual preventive measures available. In a health care system with relatively limited resources, like ours, increased QT dispersion could be used as an additional selection criterion for early coronary angiography. While our data suggest no association between the use of $\beta$ blocking agents and QT dispersion, additional studies with other compounds, especially with those known to influence QT intervals, are clearly needed.

In conclusion, our results suggest that in middle aged men with increased coronary risk and normal QT interval in resting electrocardiogram, increased $\mathrm{QT}_{\mathrm{PEAK}}$ dispersion and prolongation of maximal $\mathrm{QT}_{\mathrm{PEAK}}$ interval are independent risk factors for sudden cardiac death, but not for fatal myocardial infarction.

MV was supported by a grant from the Finnish Foundation for Cardiovascular Research

1 Demirovic J, Myerburg RJ. Epidemiology of sudden coronary death: an overview. Prog Cardiovasc Dis 1994;37: nary de $39-48$.

2 Kreger BE, Cupples A, Kannel WB. The electrocardiogram in prediction of sudden death: The Framingham Study experience. Am Heart $\mathcal{F}$ 1987;2:377-82.

3 Gillum RF. Sudden coronary death in the United States 1980-1985. Circulation 1989;79:756-65.

4 Myerburg RJ. Sudden cardiac death. Epidemiology, causes, and mechanisms. Cardiology 1987;74(suppl 2):2-9.

5 Thomas A, Knapman P, Krikler D, Davies MJ. Community study of the causes of "natural" sudden deaths. $B M F$ 1988;97:1453-7.

6 Davies MJ. Anatomic features in victims of sudden coronary death: coronary artery pathology. Circulation 1992, 85(suppl I): 19-24.

7 Roberts W, Potkin B, Solus D, Reddy S. Mode of death, frequency of healed and acute myocardial infarction, number of major epicardial coronary arteries severely narrowed by atherosclerotic plaque, and heart weight in fatal atherosclerotic coronary artery disease: an analysis of 889 patients studied at necropsy. $¥ \mathrm{Am}$ Coll Cardiol 1990;15: 196-203.

8 Corrado D, Basso C, Poletti A, Angelini A, Valente M Thiene $G$. Sudden death in the young. Is acute coronary thrombosis the major precipitating factor? Circulation 1994;90:2315-23.

9 Suhonen O, Reunanen A, Knekt P, Aromaa A. Risk factors for sudden and non-sudden coronary death. Acta Med Scand 1988;223:19-25.

10 Cupples LA, Gagnon DR, Kannel WB. Long- and short term risk of sudden coronary death. Circulation 1992;85 (suppl I): 11-18.

11 Myerburg RJ, Kessler KM, Castellanos A. Sudden cardiac death. Structure, function, and time-dependence of risk. Circulation 1992;85(suppl I):2-10.

12 Wannamethee G, Shaper AG, Macfarlane PW, Walker M. Risk factors for sudden cardiac death in middle-aged British men. Circulation 1995;91:1749-56.

13 Shaper AG, Wannamethee G, Macfarlane PW, Walker M. Heart rate, ischaemic heart disease, and sudden cardiac death in middle-aged British men. Br Heart $\mathcal{f}$ 1993;70: death in

14 Sanz G, Castaner A, Betriu A, Magrina J, Roing E, Coll S, et al. Determinants of prognosis in survivors of myocardial infarction: a prospective clinical angiographic study. $N$ Engl F Med 1982;306:1065-70.

15 Kowcy DR, Taylor JE, Marinchak RA, Rials SJ. Does programmed stimulation really help in the evaluation of patients with nonsustained ventricular tachycardia? Results of a meta-analysis. Am Heart $\mathcal{F}$ 1992;123:481-5.

16 Simson M. Noninvasive identification of patients at high risk for sudden cardiac death. Signal-averaged electrocardiography. Circulation 1992;85(suppl I):145-51.

17 Farrell TG, Bashir Y, Cripps T, Malik M, Poloniecki J, Bennett D, et al. Risk stratification for arrhythmic events in post-infarction patients based on heart rate variability, ambulatory electrocardiographic variables and the signalaveraged electrocardiogram. $\mathcal{F}$ Am Coll Cardiol 1991;18: averaged

18 Rosenbaum DS, Jackson LE, Smith JM, Garan H, Ruskin JN, Cohen RJ. Electrical alternans and vulnerability to JN, Cohen RJ. Electrical alternans and vulnerability to

19 Wentricular arrhythmias. N Engl $f$ Med 1994;330:235-41. McGovern B, et al. Out-of-hospital cardiac arrest: use of electrophysiologic testing in the prediction of long-term outcome. N Engl f Med 1988;318:19-24

20 Day CP, McComb JM, Cambell RWF. QT dispersion, an indication of arrhythmia risk in patients with long QT intervals. Br Heart f 1990;63:342-4.

21 Higham PD, Campell RWF. QT dispersion. A review. $\mathrm{Br}$ Heart $f$ 1994;71:508-10.

22 Higham PD, Furniss SS, Campell RWF. QT dispersion and components of the QT interval in ischaemia and infarction. Br Heart $\mathcal{F}$ 1995;73:32-6.

23 Perkiömäki JS, Koistinen MJ, Yli-Mäyry S, Huikuri HV. Dispersion of the QT interval in patients with and without susceptibility to ventricular tachyarrhythmias after previous myocardial infarction. $¥ \mathrm{Am}$ Coll Cardiol 1995;26: 174-9.

24 Zareba W, Moss AJ, leCessie C. Dispersion of ventricular repolarization and arrhythmic cardiac death in coronary repolarization and arrhythmic cardiac death
artery disease. Am $\mathcal{f}$ Cardiol 1994;74:550-3.

25 Barr CG, Abdelwahab N, Freeman M, Lang CC, Struthers AD. QT dispersion and sudden unexpected death in $\mathrm{AD}$. QT dispersion and sudden unexpected

26 Glancy JM, Garrat CJ, Woods KL, deBono DP. QT dispersion and mortality after myocardial infarction. Lancet 1995;345:945-8.

27 Pye M, Quinn AC, Cobbe SM. QT interval dispersion: a non-invasive marker of susceptibility to arrhythmia in patients with sustained ventricular arrhythmias. $\mathrm{Br}$ Heart $\mathcal{F}$ 1994;71:511-14

28 Frick MH, Elo O, Haapa K, Heinonen OP, Heinsalmi P, Huttunen JK, et al. The Helsinki Heart Study: primaryprevention trial with gemfibrozil in middle-aged men with dyslipidemia. Safety of treatment, changes in risk factors, and incidence of coronary heart disease. $N$ Engl $\mathcal{F} \mathrm{Med}$ 1987;317:1237-45.

29 Frick MH, Heinonen OP, Huttunen JK, Koskinen P, Mänttäri M, Manninen V. Efficacy of gemfibrozil in dyslipidemic subjects with suspected heart disease. An ancillary study in the Helsinki Heart Study frame population. Ann Med 1993;25:41-5.

30 Heinonen OP, Huttunen JK, Manninen V, Mänttäri M, Koskinen P, Tenkanen L, et al. The Helsinki Heart Study: Koskinen P, Tenkanen $L$, et al. The Helsinki Heart Study: coronary heart disease incidence during
low-up. $\mathcal{F}$ Intern Med 1994;235:31-9.

31 Lepeschkin E, Surawicz B. The measurement of the QTinterval of the electrocardiogram. Circulation 1952;6: 378-87.

32 Bland $M$, Altman DG. Statistical methods for assessing agreement between two methods of clinical measurement. Lancet 1986; i:307-10.

33 Karjalainen J, Viitasalo M, Mänttäri M, Manninen V. Relation between QT-intervals and heart rates from 40 to 120 beats per minute in resting electrocardiogram of men and a simple method to adjust QT values. $\mathscr{f} \mathrm{Am}$ Coll Cardiol 1994;23:1547-53.

34 Cohen I, Giles W, Noble D. Cellular basis for the $T$ wave of the electrocardiogram. Nature 1976;262:657-61.

35 El-Sherif N, Zeiler RH, Craelius W, Gough WB, Henkin R. QTU prolongation and polymorphic ventricular tachyarrhythmias due to bradycardia-dependent early afterdepolarizations. Circ Res 1988;63:286-315.

36 Moreno FL, Villanueva T, Karagounis LA, Anderson IL, for the TEAM-2 study investigators. Reduction in QT interval dispersion by successful thrombolytic therapy in acute myocardial infarction. Circulation 1994;90:94-100. 